\title{
Responsabilidad, inclusión y gobernanza global: Una crítica de la concepción estatista de los derechos humanos *
}

\section{Democratic Accountability and Global Governance: Challenging the state-centric Conception of Human Rights}

\author{
CRISTINA LAFONT \\ Northwestern University \\ clafont@u.northwestern.edu
}

RESUmen. En este ensayo analizo algunas dificultades conceptuales asociadas a la exigencia de que las instituciones globales adquieran un grado mayor de legitimidad democrática. En ausencia de un Estado mundial, puede parecer inconsistente exigir que las instituciones globales sean responsables ante todos los que han de acatar sus decisiones y al mismo tiempo insistir en que los miembros de dichas instituciones, en tanto que representantes de sus respectivos Estados, mantengan las responsabilidades especiales que tienen con los ciudadanos de sus propios países. Esta dificultad parece insuperable a la luz de la extendida aceptación de la concepción de los derechos humanos centrada en el Estado, según la cual los Estados, y sólo ellos, son los responsables principales de proteger los derechos de sus ciudadanos. Contra esta concepción, defiendo la plausibilidad de una concepción alternativa, pluralista de las obligaciones derivadas de los derechos humanos. Para ello argumento que, si se tiene en cuenta la distinción tripartita entre la obligación de respetar,
ABstract. In this essay I analyze some conceptual difficulties associated with the demand that global institutions be made more democratically accountable. In the absence of a world state, it may seem inconsistent to insist that global institutions be accountable to all those subject to their decisions while also insisting that the members of these institutions, as representatives of states, simultaneously remain accountable to the citizens of their own countries for the special responsibilities they have towards them. This difficulty seems insurmountable in light of the widespread acceptance of a state-centric conception of human rights, according to which states and only states bear primary responsibility for the protection of their citizens' rights. Against this conception, I defend an alternative, pluralist conception of human rights obligations. I argue that, once the distinctions between the obligations to respect, protect and fulfill human rights are taken into account, no conceptual difficulty remains in holding states and non-state actors accoun-

* La traducción del original inglés ha sido realizada por José Luis López de Lizaga. Agradezco a los participantes en el Congreso sobre Democracia Deliberativa y Justicia Global (Fráncfort, Alemania) y en el Workshop sobre Democracia Global (Prato, Italia) por sus estimulantes preguntas y comentarios sobre versiones anteriores de este ensayo. 
proteger y realizar los derechos humanos, no hay ninguna dificultad conceptual en exigir que tanto los Estados como los actores no estatales se responsabilicen por sus respectivas obligaciones en materia de derechos humanos.

Palabras clave: actores no estatales, Banco Mundial, Beitz, derechos humanos, FMI, gobernanza global, inclusión, instituciones globales, OMC, responsabilidad democrática. table for their respective human rights obligations.

Key words: accountability, Beitz, global governance, global institutions, human rights, IMF, inclusion, non-state actors, World Bank, WTO.

Prácticamente todos los filósofos políticos coinciden en que la democracia es superior a cualquier otro sistema político a nivel nacional. Por eso puede sorprender que pocos teóricos recomienden la democracia como un modelo adecuado a nivel global. Sin embargo, sería un error inferir de ahí que hay alguna característica de la democracia que los detractores del ideal de una democracia global rechazan. Lo que la mayoría de estos detractores encuentra objetable es la idea de un único sistema político con un gobierno mundial. Ni que decir tiene que aún les parecería más objetable si se tratase de un gobierno no democrático, totalitario. De hecho, lo que estos autores temen es que un Estado mundial se convertiría inevitablemente en un Estado totalitario debido a su extraordinaria acumulación de poder, aún si se tratase formalmente de un Estado democrático. Ahora bien, incluso si se acepta que un Estado mundial no es deseable, podría haber ciertos rasgos de la democracia que, convenientemente adaptados, podrían aplicarse a instituciones globales. La democratización transnacional podría llevarse a cabo sin un gobierno mundial. Concebida de este modo más modesto, la aspiración a la democracia global parece hallarse bastante extendida en la literatura sobre gobernanza global. Al menos la queja de que las actuales estructuras de gobernanza global carecen de legitimidad democrática está muy extendida, lo cual sugiere que algún tipo de democratización a nivel transnacional sería deseable. A continuación quisiera explorar esta posibilidad. En particular, voy a centrarme en el ideal democrático de inclusión, a fin de examinar hasta qué punto ofrece un objetivo apropiado para mejorar la legitimidad de las instituciones globales en ausencia de un Estado mundial.

La democracia puede definirse básicamente como la autorización colectiva de leyes y medidas políticas por todos aquellos sujetos a las mismas. Esta definición implica dos aspectos de la exigencia de inclusión política. Un primer aspecto concierne a la soberanía, es decir, a la cuestión de quién toma las decisiones en el sistema político. El ideal democrático de inclusión en los procesos de decisión política se expresa normalmente como el ideal de soberanía popular: en una democracia, aquellos que están sometidos a la ley son al mismo tiempo sus autores. Ahora bien, en las democracias representativas el ideal de soberanía popular queda reducido típicamente a la soberanía electo- 
ral: los ciudadanos delegan en sus representantes oficiales la mayor parte de las decisiones acerca de leyes y medidas concretas, pero mantienen el poder político de elegir a sus representantes y, en casos especiales, pueden decidir directamente algunas leyes o medidas políticas importantes mediante referendos populares. El requisito de que los ciudadanos tengan la última palabra en algunas decisiones políticas importantes es la diferencia esencial entre la democracia y las formas no democráticas de organización política. Dicho requisito encuentra expresión institucional en los derechos políticos de participación en los procesos de toma de decisiones que se extienden a todos los ciudadanos adultos.

Ahora bien, si todos los ciudadanos tuviesen la última palabra en todas las decisiones políticas a las que están sujetos, la soberanía sería la única dimensión del ideal democrático de inclusión política. Pero precisamente en las democracias representativas, en las que los ciudadanos delegan en sus representantes la mayor parte de las decisiones políticas, la exigencia democrática de inclusión política impone constricciones normativas no sólo en relación con la soberanía de los ciudadanos, sino también en relación con la responsabilidad de sus representantes. De acuerdo con el ideal democrático, éstos están obligados a responder de sus decisiones políticas ante todos aquellos que están sometidos a ellas. ${ }^{1} \mathrm{Si}$ interpretamos la responsabilidad política en términos del modelo representado-representante [principal-agent], el rasgo específico de la responsabilidad política democrática (a diferencia de otros tipos de responsabilidad ${ }^{2}$ ) consiste en que todos aquellos que están sujetos a las decisiones políticas del agente representante deben ser reconocidos como sus representados. Como sucede con la concepción democrática de la soberanía, aquí también la clave es el requisito de inclusión política, es decir, la congruencia requerida entre los responsables de tomar decisiones políticas y todos los que están sometidos a las mismas. La diferencia obvia es que mientras que la soberanía democrática requiere que todos los que han de acatar las de-

${ }^{1}$ En el contexto de esta argumentación interpretaré la responsabilidad política en términos del modelo representado-representante [principal-agent]. Tal como lo define Keohane (2003), «una relación de responsabilidad política es una relación en la que un individuo, grupo $\mathrm{u}$ otra entidad exige que un agente informe de sus actividades y tiene la capacidad de imponer sanciones al agente. Hablamos de una relación de responsabilidad autorizada o institucionalizada cuando la exigencia de informar y el derecho de sancionar son comprendidos y aceptados por ambas partes» (p. 139). Dado que aquí me interesa en concreto el grado de inclusión presente en las estructuras de responsabilidad de las instituciones globales, el modelo de representado-representante es muy útil para mi análisis. Sin embargo, no quiero sugerir con ello que el modelo de responsabilidad de representado-representante es o tenga que ser necesariamente el único modelo, o el más adecuado, cuando se reflexiona sobre las estructuras emergentes de gobernanza global. Para un interesante análisis de las dificultades de aplicación a escala global del modelo tradicional de representado-representante, cf. Cohen y Sabel (2005).

2 Por ejemplo, responsabilidad jerárquica y supervisora, responsabilidad legal, responsabilidad basada en la reputación, o responsabilidad ante el mercado. Para una discusión detallada de diversos tipos de responsabilidad, cf. Kehoane y Nye (2003). 
cisiones estén incluidos en el proceso mismo de toma de decisión, la responsabilidad democrática sólo requiere que los que toman las decisiones actúen como representantes de todos los que tienen que acatarlas y, por tanto, tengan en cuenta los intereses de todos ellos en la toma de decisiones.

Debido a esas dos dimensiones del ideal democrático de inclusión el término «responsabilidad democrática» [democratic accountability] puede entenderse en varios sentidos. Entendido como respuesta a la pregunta ante quién son responsables los representantes políticos, el término indica el requerimiento democrático de que los representantes den cuenta de sus decisiones ante todos los que están sujetos a las mismas. Sin embargo, este término puede entenderse también como respuesta a una pregunta diferente, a saber, mediante qué procedimientos puede garantizarse dicha responsabilidad. En este segundo sentido, el término se entendería como sinónimo de lo que habitualmente se denomina «responsabilidad electoral» [electoral accountability] y se referiría específicamente al requerimiento democrático de garantizar la responsabilidad de los representantes ante todos los que han de acatar sus decisiones mediante el poder que estos últimos tienen de destituirles o reemplazarles en elecciones democráticas periódicas. Si entendemos el término en este segundo sentido, «responsabilidad democrática» incluye soberanía electoral. Sin embargo, si lo entendemos en el primer sentido, la responsabilidad electoral es un tipo de responsabilidad democrática pero no el único posible. En las democracias constitucionales hay otros mecanismos, además de las elecciones, para garantizar la responsabilidad de los representantes ante todos aquellos que han de acatar sus decisiones. Dado que aquí no voy a analizar la dimensión de soberanía del principio de inclusión, voy a utilizar a partir de ahora el término «responsabilidad inclusiva» en vez de «responsabilidad democrática» para evitar toda confusión con la noción de responsabilidad electoral.

Huelga decir que ni el requisito fuerte de responsabilidad electoral ni el requisito más débil de responsabilidad inclusiva son satisfechos en prácticamente ninguna sociedad democrática existente en la actualidad, pues en la mayoría de ellas hay muchos individuos que, por no ser ciudadanos, están enteramente excluidos del proceso político y, sin embargo, están sujetos a las decisiones resultantes de dicho proceso. Con todo, el desajuste a nivel nacional entre quienes toman las decisiones y quienes tienen que acatarlas palidece en comparación con ese mismo desajuste a nivel global, en el que me centraré a continuación.

No es necesario un análisis exhaustivo para convenir en que ninguno de los dos requisitos de legitimidad democrática es satisfecho por las instituciones de gobernanza global actuales. El más obvio de estos incumplimientos es, por supuesto, la carencia de soberanía electoral de todos los que están sometidos a las decisiones de instituciones globales. Pero debo confesar que, desgraciadamente, no veo cómo las actuales instituciones de gobernanza global 
podrían transformarse en instituciones participativas globales sin tener que establecer un sistema político único con un gobierno mundial. Dado que, en mi opinión, la soberanía electoral es un rasgo crucial de la democracia, celebraría sin duda cualquier propuesta institucional que indicara cómo democratizar las actuales instituciones de gobernanza global de modo que se otorgue la última palabra en algunas decisiones importantes a todos aquellos que están sujetos a las mismas, sin establecer para ello un único sistema político a nivel global. ${ }^{3}$ Pero dejando abierta de momento la cuestión de la soberanía electoral quisiera centrarme a continuación en el requisito de inclusión inherente a la concepción democrática de la responsabilidad política.

Aunque existe un amplio consenso acerca del déficit de responsabilidad democrática de las actuales instituciones de gobernanza global (tales como la ONU, el FMI, la OMC o el Banco Mundial), hay mucho menos acuerdo acerca del remedio apropiado para subsanar dicha carencia. De hecho, la propuesta de aplicar criterios intraestatales de responsabilidad democrática a las instituciones globales no sólo encuentra oposición entre quienes cuestionan su viabilidad, ${ }^{4}$ sino incluso entre quienes cuestionan directamente su deseabilidad, a la luz del coste potencial que dicha aplicación supondría en términos de otras cualidades y metas valiosas de las instituciones implicadas. ${ }^{5}$ Sin embargo, la inclusión es un aspecto de la responsabilidad democrática cuya deseabilidad parece difícilmente cuestionable. El principio normativo según el cual los que toman las decisiones políticas deben responder ante quienes las han de acatar, por usar la formulación de $\mathrm{Held}^{6}$, parece tan válido a nivel

${ }^{3}$ Hay muchas propuestas en esta dirección, por ejemplo el uso de referendos que se extiendan transversalmente a varias naciones, sea a nivel regional o global, cuando esté en juego la implementación de regulaciones globales controvertidas. Cf. Held 2004b, p. 385. No está claro, sin embargo, cómo podrían implementarse adecuadamente dichas propuestas sin una única estructura política jerárquica.

4 Puede encontrarse un ejemplo en Dahl 1999.

5 Los dilemas relevantes aquí no son muy diferentes de los que existen a nivel nacional. Aumentar la publicidad y la transparencia de los procesos de decisión incrementando el acceso público a la información puede perjudicar la capacidad de la institución de tomar las decisiones más eficaces, o puede conducir a la polarización y exacerbar la inestabilidad. Usar reglas de consenso en el proceso de decisión pueden conducir a la inacción y a conceder una influencia excesiva a países pequeños, mientras que su sustitución por la regla de la mayoría puede marginar a los países pequeños y silenciar asuntos importantes, etc. Para un análisis detallado de algunos de estos dilemas en relación con las instituciones financieras globales, cf. Kahler (2004).

6 Adopto la terminología de Held para referirme a lo que él llama «el principio de inclusividad» o «el principio de equivalencia entre el que toma las decisiones y el afectado por ellas» (cf. Held 2004, pp. 13, 103; y 2005, pp. 246-48). Sin embargo, en este artículo me centro exclusivamente en la dimensión de la responsabilidad y no abordo la dimensión de la soberanía del principio de inclusión. Held no distingue explícitamente estas dos dimensiones, y a veces emplea el principio de un modo que implica soberanía, por ejemplo cuando afirma que, de acuerdo con el principio, quienes deben acatar las decisiones tienen que «tener voz» en el proceso de decisión. Si por «tener voz» se quiere decir que quienes acatan las decisiones deberían 
transnacional como a nivel nacional. Ahora bien, lo que parece cuestionable, y de hecho ha sido cuestionado, es si una responsabilidad inclusiva puede lograrse a nivel global sin un Estado mundial. Y aquí las razones que se aducen no son tanto empíricas cuanto más bien conceptuales. Dejando de lado la cuestión empírica de la viabilidad, desde un punto de vista puramente normativo parece que si queremos mantener la división del espacio político por Estados, tenemos que mantener la correspondiente división de los representados [principals] por Estados. Si éste es el caso, sería una confusión conceptual querer mantener la importancia normativa de los Estados y, al mismo tiempo, exigir una responsabilidad inclusiva a nivel global.

A continuación quisiera argumentar a favor de una posible salida a este dilema conceptual. Mis pretensiones, sin embargo, son bastante modestas. No aspiro a proporcionar ninguna solución a las difíciles cuestiones de implementación que acompañan a toda propuesta de reforma institucional. Mi argumentación no es un intento de enmendar todos los déficits de legitimidad democrática de las instituciones globales actuales. ${ }^{7}$ Sólo pretendo mostrar que no hay nada conceptualmente problemático en considerar que las instituciones globales deben ser responsables ante todos aquellos que han de acatar sus decisiones al tiempo que los miembros de dichas instituciones, en tanto que representantes de sus respectivos Estados, mantienen responsabilidades especiales hacia los ciudadanos de sus propios países.

\section{¿Es posible una responsabilidad inclusiva sin un Estado mundial?}

Como ya he dicho, una de las principales dificultades a que se enfrentan las estructuras emergentes de gobernanza global es la falta de congruencia entre quienes toman las decisiones y quienes han de acatarlas. ${ }^{8}$ Este desajuste ge-

tener también la capacidad de tomar algunas de dichas decisiones, entonces se trata de un principio de responsabilidad más fuerte que aquél al que yo me estoy refiriendo aquí, ya que incluye cierta exigencia de soberanía. En el sentido, más débil, en que aquí empleo yo el principio, la responsabilidad inclusiva no requiere que quienes deben acatar las decisiones «tengan voz» en el proceso de decisión, sino únicamente que sus intereses y derechos sean tenidos en cuenta por aquellos que toman las decisiones; o por decirlo con la formulación de la norma de inclusión que proponen Cohen y Sabel, el principio requiere que en el proceso de decisión esos intereses y derechos no se traten «como si no contaran en absoluto, más allá del mínimo humanitario debido incluso en ausencia de toda cooperación» (Cohen y Sabel, 2006, p. 154).

7 El objetivo de mi argumento es bastante limitado, entre otras cosas porque se centra exclusivamente en la dimensión de responsabilidad del principio de inclusión, y no aborda ninguna de las importantes cuestiones relativas a la dimensión de soberanía (por ejemplo, cómo lograr una representación igualitaria entre los miembros de las instituciones globales, qué reglas de decisión deberían seguir, etc.).

8 Para un excelente análisis de este problema, cf. Keohane 2003. En general, estoy muy de acuerdo con dicho análisis. Ciertamente comparto la opinión de Keohane cuando afirma que entre todas las carencias de responsabilidad que encontramos actualmente en las instituciones glo- 
nera un tipo muy especial de déficit de responsabilidad política. El problema no es que quienes toman las decisiones pueden eludir fácilmente su responsabilidad cuando los que han de acatarlas no tienen ninguna voz en el proceso de decisión. El problema específico a nivel global es que ni siquiera se supone que quienes toman las decisiones han de responder ante todos los que han de acatarlas. Los países poderosos pueden imponer regulaciones económicas globales con consecuencias devastadoras para muchos de los que han de acatarlas, y esto sucede no porque los delegados de esos países en las instituciones financieras internacionales eluden su responsabilidad política, sino precisamente porque actúan en nombre de dicha responsabilidad ${ }^{9}$. Dado que los delegados se supone que son responsables ante los ciudadanos de sus propios países tanto para decisiones nacionales como transnacionales, no es de extrañar que se consideren sujetos a la obligación de proteger y promover los intereses y los derechos de sus propios ciudadanos, y no los de todos aquellos que han de acatar sus decisiones. Por consiguiente, reforzar la responsabilidad política de los delegados ante los ciudadanos de sus propios países sólo puede empeorar el problema, en lugar de mejorarlo. A falta de algún rasgo institucional destinado a corregir la fragmentación entre los diversos (y sumamente desiguales) representados, no hay razón alguna para esperar que quienes toman las decisiones en las instituciones globales sean políticamente responsables ante todos aquellos que tienen que acatar dichas decisiones. ${ }^{10}$

bales, «los problemas normativos más serios surgen en relación con lo que llamo la responsabilidad externa: la responsabilidad hacia personas que quedan fuera de la entidad y cuyas vidas se ven afectadas por ésta» (p. 141). Sin embargo, encuentro que esta distinción entre la responsabilidad interna y externa es problemática a la luz de la propuesta que quiero defender aquí. De acuerdo con esta distinción, hablamos de «responsabilidad interna» cuando el representado y el agente están «vinculados institucionalmente», ya sea porque el representado provee de recursos al agente, ya porque ha autorizado directamente al agente a actuar en su nombre. Un ejemplo paradigmático de este tipo de relación de responsabilidad es la relación que existe entre los ciudadanos y sus representantes en las instituciones globales. Por el contrario, la «responsabilidad externa» se da en ausencia de toda conexión institucional entre el agente y lo que Keohane llama, por este motivo, «representados supuestos» [«would-be principals»]. Esta responsabilidad se mantiene en virtud del hecho de que éstos se ven afectados por las decisiones de aquéllos. Keohane pone como ejemplo la relación entre el Banco Mundial y los granjeros africanos afectados por las medidas del Banco. El problema principal de esta distinción es que cualquier propuesta que apunte a establecer un vínculo institucional entre los afectados por las decisiones globales y los agentes que toman esas decisiones no parece poder acomodarse en ninguna de las dos categorías. En la medida en que dicho vínculo se basaría meramente en el impacto de las decisiones (y no en la autorización o los recursos), caería bajo la categoría de «responsabilidad externa» de Keohane; pero en la medida en que se institucionalizaría en el interior de las agencias en cuestión, caería también bajo la categoría de «responsabilidad interna». La ironía que subyace a esta dificultad de la distinción de Keohane consiste en que, si bien este autor es muy consciente de la importancia normativa de hacer que las instituciones de gobernanza global respondan ante todos aquellos que se ven afectados por sus decisiones, su distinción no parece dejar espacio para la posibilidad de establecer mecanismos institucionales para alcanzar ese objetivo.

9 Para una dramática ilustración de este problema cf. nota 45.

10 Dejo de lado los obvios problemas adicionales que surgen del hecho de que los repre- 
A la luz de este desajuste estructural, muchos autores concluyen que sólo en el marco de un Estado mundial sería posible establecer una responsabilidad inclusiva a nivel global. Los representantes en ese Estado mundial serían responsables ante todos los ciudadanos del mundo, que conformarían así una única parte representada. Como sucede a menudo, el acuerdo en torno a esta conclusión está abierto a la usual alternativa argumentativa entre el modus ponens y el modus tollens, de modo que algunos autores ofrecen este argumento para sostener que la democracia transnacional necesita un Estado mundial, ${ }^{11}$ mientras que otros lo ven como una refutación directa de la pretensiones cosmopolitas de justicia global que restan importancia normativa a los Estados. El artículo de Nagel «The Problem of Global Justice» ofrece un claro ejemplo de esta última estrategia. Nagel caracteriza del modo siguiente la dificultad estructural que está aquí en juego:

Creo que las nuevas formas de gobernanza global comparten con las anteriores una relación marcadamente indirecta con los ciudadanos individuales, y esto es moralmente importante. Todas estas redes institucionales reúnen a representantes de funciones e instituciones del Estado, no a representantes de individuos. Esas instituciones son responsables ante sus propios ciudadanos y quizás tienen una función importante en el sustento de la justicia social para esos ciudadanos. Pero una red global o regional no tiene una responsabilidad similar de lograr la justicia social para el conjunto de las ciudadanías de todos los Estados implicados, una responsabilidad que, si existiese, tendrían que ejercer colectivamente los representantes de los Estados miembros ${ }^{12}$.

La afirmación contrafáctica de Nagel subraya el dilema normativo: o bien los Estados y sus representantes tienen la responsabilidad de proteger los intereses y derechos de sus propios ciudadanos, o bien se necesita un Estado mundial cuyos representantes tendrían la responsabilidad colectiva de proteger los intereses y derechos de todos los ciudadanos del mundo por igual. Lo que no es posible es preservar la asignación de responsabilidad a los Estados,

sentados más próximos a los delegados en las instituciones financieras globales son los gobiernos, y que su agenda política y su percepción del interés nacional a menudo difieren de la que tienen sus ciudadanos. Así sucede especialmente (aunque no exclusivamente) en el caso de los gobiernos de países que no tienen estructuras democráticas de responsabilidad política.

11 Un ejemplo de esta línea de argumentación puede encontrarse en Schmalz-Bruns 2007.

12 Nagel 2005, pp. 139-140. El argumento de Nagel en este pasaje aborda dos cuestiones a la vez. Una es la cuestión de la «inclusión», es decir, la cuestión de si las instituciones globales tienen responsabilidades hacia todos los ciudadanos del mundo, a pesar de que sus miembros tienen responsabilidades especiales únicamente con los ciudadanos de los países a los que representan. La otra es la cuestión del «contenido» de esas responsabilidades, es decir, la cuestión de si las responsabilidades de las instituciones globales hacia los ciudadanos del mundo son tan fuertes como las responsabilidades de justicia social que las instituciones nacionales tienen hacia sus propios ciudadanos. En este artículo me centro únicamente en la primera cuestión, pero en la última sección indico muy brevemente cómo se relaciona la propuesta que defiendo aquí con las afirmaciones de Nagel acerca de la segunda cuestión. 
y simultáneamente reclamar una responsabilidad inclusiva de instituciones globales cuyos participantes representan a Estados nacionales, y no a ciudadanos del mundo. El problema no es la discrepancia habitual entre expectativas normativas y las realidades de la política de poder, sino el conflicto directo entre las expectativas normativas mismas. Como ya hemos mencionado, la objeción no es empírica, sino conceptual.

Dado que la alternativa de un Estado mundial no me parece atractiva, me parece más prometedor investigar en detalle el alcance preciso y el significado exacto de la asignación a los Estados de la responsabilidad de proteger los intereses y derechos de sus ciudadanos. Esta asignación forma parte de la concepción dominante de las obligaciones derivadas de los derechos humanos, según la cual los Estados tienen la responsabilidad fundamental de proteger los derechos humanos de sus propios ciudadanos. A pesar de la prevalencia de esta concepción, vale la pena examinar sus credenciales normativas pues la fragmentación de los representados, que hace parecer incoherente la expectativa de una responsabilidad inclusiva sin un Estado mundial, es una consecuencia directa de la asignación de responsabilidades centrada en el Estado que caracteriza a dicha concepción. Anticipando la argumentación que desarrollaré a continuación, estoy de acuerdo con dos de las afirmaciones que conducen al dilema normativo señalado por Nagel. Estoy de acuerdo en que algunos supuestos de la concepción de los derechos humanos centrada en el Estado son incompatibles con la adscripción de responsabilidad inclusiva a las instituciones de gobernanza global, y estoy de acuerdo también en que la formación de un Estado mundial es el único modo de compatibilizar la responsabilidad inclusiva a nivel global con la concepción estatista de las obligaciones derivadas de los derechos humanos. Pero estas dos afirmaciones no constituyen un verdadero dilema, puesto que queda una alternativa bastante más atractiva. En lugar de resignarnos a aceptar un Estado mundial o renunciar a la exigencia de responsabilidad inclusiva a nivel global, parece mejor rechazar los supuestos problemáticos de la concepción de los derechos humanos centrada en el Estado.

\section{Una crítica de la concepción de los derechos humanos centrada en el Estado 13}

En su libro The Idea of Human Rights, Charles Beitz ofrece una descripción paradigmática de la concepción de los derechos humanos centrada en el Estado

13 En lo que sigue debería quedar claro que mi propósito no es poner en cuestión la responsabilidad fundamental de los Estados en la protección de los derechos humanos de sus ciudadanos. Estoy completamente de acuerdo con la opinión de que debe recaer en los Estados la responsabilidad principal en esta materia. El aspecto de la concepción centrada en el Estado que me propongo cuestionar es la afirmación de que sólo los Estados tienen la responsabilidad de proteger los derechos humanos y, por tanto, los actores no estatales no tienen obligaciones en materia de derechos humanos. 
que él defiende. Beitz explica que «la idea central de los derechos humanos internacionales es que los Estados son responsables de satisfacer ciertas condiciones en el modo en que tratan a su propia población, y que el fracaso o el previsible fracaso de esta tarea puede justificar alguna forma de intervención correctiva o preventiva por parte de la comunidad internacional o de los agentes que actúan en su nombre.» ${ }^{14}$ En consecuencia, la práctica de los derechos humanos «consiste en un conjunto de normas de regulación de la conducta de los gobiernos, y de una gama de acciones abierta a varios agentes para los que el hecho de que un gobierno no se atenga a esas normas proporciona razones.» ${ }^{15}$ De acuerdo, pues, con la concepción de los derechos humanos centrada en el Estado, los Estados tienen la responsabilidad fundamental de proteger y promover los derechos e intereses de sus propios ciudadanos. La comunidad internacional tiene alguna responsabilidad en la protección de los derechos humanos, pero a diferencia de lo que sucede con los Estados, esta responsabilidad es secundaria (o residual ${ }^{16}$ ), y ello en dos sentidos. En primer lugar, la responsabilidad de la comunidad internacional es secundaria en el sentido de que sólo se activa cuando los Estados son remisos o incapaces de proteger los derechos de sus propios ciudadanos. En segundo lugar, la responsabilidad de la comunidad internacional es secundaria en el sentido de que no se espera que sustituya la función protectora de los Estados. A través de las diferentes instituciones que actúan en su nombre, la comunidad internacional puede proporcionar asistencia (temporalmente) a los Estados, pero no se espera que ninguna de estas instituciones aporte el tipo de protección, títulos y servicios que los Estados proporcionan a sus ciudadanos. La función protectora de la comunidad internacional se limita a exigir responsabilidades a los Estados por el trato que dan a sus propios ciudadanos. Esta función se ejerce mediante diversos agentes internacionales y transnacionales, y mediante diversas medidas que incluyen la supervisión del cumplimiento por parte de los Estados de los estándares internacionales de derechos humanos, el ofrecimiento de incentivos económicos y de otros tipos para promover ese cumplimiento (por ejemplo, la ayuda internacional condicionada o el trato preferencial en las relaciones económicas), o el uso de medidas coercitivas tales como la amenaza de sanciones económicas o diplomáticas e incluso de intervención militar en casos de graves violaciones de los derechos humanos.

Aunque la concepción de los derechos humanos centrada en el Estado está ampliamente aceptada, tiene algunas consecuencias problemáticas. Un rasgo sorprendente de esta concepción es su llamativo silencio acerca de las obligaciones de actores no estatales (desde los individuos ${ }^{17}$ a las corporacio-

14 Beitz 2009, p. 13.

15 Beitz 2009, p. 44.

16 Cf. Goodin 2003, pp. 76 y ss.

17 La posibilidad de procesar a los líderes de grupos no estatales de rebeldes armados por las violaciones de derechos humanos, tales como el genocidio o la limpieza étnica, con inde- 
nes multinacionales ${ }^{18} \mathrm{o}$ las instituciones financieras internacionales como la OMC, el FMI o el Banco Mundial). Si en los Estados recae la responsabilidad primordial de proteger los derechos humanos de sus propios ciudadanos y la responsabilidad secundaria de la comunidad internacional se agota en exigir responsabilidad a los Estados por el trato que dan a sus ciudadanos, parece que los actores no estatales no tienen ninguna obligación de proteger los derechos humanos $\mathrm{y}$, en consecuencia, la comunidad internacional no tiene la obligación de exigir responsabilidades a dichos actores por el impacto de sus acciones o decisiones en la protección de los derechos humanos. Sin embargo, en las condiciones actuales de globalización es cada vez más evidente que las regulaciones económicas globales adoptadas por ciertos actores no estatales (como la OMC, el FMI o el Banco Mundial) pueden tener un tremendo impacto en la posibilidad de proteger los derechos humanos a escala mundial. Ahora bien, si éste es el caso, ¿no es poco plausible sostener que estas instituciones no tienen ninguna obligación en materia de derechos humanos? Y lo que es peor, ¿cómo puede la comunidad internacional responsabilizar a los Estados de las consecuencias de regulaciones globales que no está realmente en sus manos determinar? ¿No debería la comunidad internacional exigir responsabilidades a aquellos actores cuyas decisiones y acciones impiden la protección de los derechos humanos, tanto si son Estados como si no lo son, en lugar de exigir responsabilidades a los Estados por decisiones y acciones que no están bajo su control?

Es cierto que, de acuerdo con la concepción centrada en el Estado, cuando los Estados son incapaces de proteger los derechos humanos debido a factores externos, no se les considera responsables del mismo modo en que lo serían si fueran capaces de proporcionar esa protección, pero se negaran a hacerlo. En tales casos no serán sometidos a sanciones coercitivas, y en lugar de eso quizás reciban asistencia internacional. Pero el hecho de que no se considere a los Estados responsables de regulaciones y decisiones que escapan a su control difícilmente puede hacer que la concepción estatista sea normativamente convincente, si a los autores de dichas regulaciones y decisiones tampoco se les puede considerar responsables. La imposibilidad de cubrir ese hiato de responsabilidad inherente a la concepción estatista conduce a resulta-

pendencia de todo reconocimiento de su estatus oficial como agentes de un Estado, es un ejemplo de la desconexión entre la concepción de los derechos humanos centrada en el Estado y la práctica actual en materia de derechos humanos. Sobre este asunto cf. Clapham 2006, pp. 271-316.

18 La posibilidad de procesar a las corporaciones multinacionales en tribunales de Estados Unidos por violaciones de la legislación internacional de derechos humanos en virtud de la Ley de Reclamación por Agravios contra Extranjeros (ATCA) es otro ejemplo de la actual práctica de derechos humanos que no es posible explicar desde la concepción centrada en el Estado. Para una buena panorámica de las regulaciones internacionales que cubren las obligaciones de corporaciones multinacionales en materia de derechos humanos, cf. Clapham 2006, pp. 195-270. Cf. también Alston 2005. 
dos poco plausibles también en relación con las responsabilidades secundarias de la comunidad internacional. Si por hipótesis una regulación económica global impide la protección de los derechos humanos de los ciudadanos de algunos Estados, proporcionar asistencia a dichos Estados parece el remedio equivocado a adoptar por parte de la comunidad internacional. La respuesta apropiada sería atajar el problema de raíz, y cambiar la regulación problemática en cuestión. Pero esta respuesta, intuitivamente obvia, no puede acomodarse en la concepción estatista. Veamos por qué.

Podría parecer que, así como la concepción estatista puede reconocer que la responsabilidad secundaria de la comunidad internacional en relación con la protección de los derechos humanos está distribuida entre instituciones internacionales y transnacionales de muy diversa índole (agencias de derechos humanos de la ONU, Estados, ONGs, etc.), también puede reconocer que los remedios apropiados para cumplir correctamente con esta responsabilidad pueden ser muy diversos. Beitz ofrece un ejemplo de esta estrategia argumentativa en The Idea of Human Rights. Aunque defiende explícitamente una concepción de los derechos humanos centrada en el Estado, proporciona una lista de seis «paradigmas de implementación»o «aplicación» de los derechos humanos, mediante los cuales diversos agentes pueden intentar prevenir o remediar los fallos de los Estados en la protección de los derechos humanos. Uno de esos paradigmas incluye la posibilidad de cambiar una regulación global. Beitz denomina a este tipo de acción «adaptación externa», y explica del siguiente modo la diferencia crucial entre este tipo de acción y los otros cinco tipos paradigmáticos de implementación (que él denomina «responsabilidad», «incentivos», «asistencia», «oposición interna», y «coerción»):

Los primeros cinco paradigmas consisten en mecanismos que apuntan a influir en el comportamiento de agentes domésticos (...). Pero puede suceder que los obstáculos al cumplimiento de los derechos humanos por parte de un gobierno se encuentren en las políticas de otros Estados, actores multilaterales o regímenes internacionales, más bien que en su propia falta de recursos, capacidad o voluntad. Considérese, por ejemplo, las políticas comerciales que discriminan los productos agrícolas, o las leyes de propiedad intelectual en vigor en el derecho internacional que incrementan el coste de los productos farmacéuticos. Si fuese verdad que sin las adaptaciones de estas políticas «externas» un gobierno no estaría en condiciones de asegurar la protección de los derechos humanos de su propia población, entonces la reforma de estas políticas podría considerarse plausiblemente como un medio de «implementación» de los derechos humanos, aunque esto pueda parecer un uso abusivo del término (Quizás parezca menos abusivo si recordamos el reconocimiento, contenido en la Declaración, de la necesidad de «un orden internacional (...) en el que los derechos humanos puedan realizarse plenamente»). En cualquier caso, está claro que las adaptaciones externas forman parte de los tipos de acción para los que a veces se buscan 
justificaciones cuando se consideran cuestiones relacionadas con los derechos humanos. ${ }^{19}$

No es sorprendente que Beitz considere un uso lingüístico abusivo la inclusión de esta forma de acción como un modo de «implementar» la protección de los derechos humanos. A la luz de su descripción de la práctica de los derechos humanos como consistente «en un conjunto de normas para la regulación de la conducta de los gobiernos» (p. 144), la inclusión de este tipo de acción resulta sumamente anómala. Como Beitz mismo señala, una clara diferencia entre este tipo de acción y los otros cinco estriba en que el objetivo de la misma no son los Estados afectados (es decir, sus gobiernos), sino actores no estatales. Desde la perspectiva de la concepción estatista de los derechos humanos es obvio por qué medidas que apuntan a influir en el comportamiento de los Estados son formas apropiadas por parte de la comunidad internacional de cumplir sus obligaciones (secundarias) en materia de derechos humanos, dado que, de acuerdo con esta concepción, la obligación de la comunidad internacional consiste en hacer que los Estados cumplan su obligación de proteger los derechos humanos de sus propios ciudadanos. Pero ¿cómo puede justificarse como un medio de «implementar» la protección de los derechos humanos una medida cuyo objetivo es influir en el comportamiento de un actor que no tiene la responsabilidad de proteger los derechos humanos? Más aún, ¿cómo podría emprender el actor no estatal la reforma de las regulaciones en cuestión en nombre de la implementación de los derechos humanos, sin reconocer y aceptar con ello la obligación de proteger los derechos humanos? 20

Sin duda Beitz tiene razón al indicar que consideraciones sobre derechos humanos se emplean a menudo en los foros internacionales para justificar la necesidad de este tipo de acción. Pero eso no significa que Beitz pueda justificar este rasgo peculiar de la actual práctica discursiva de los derechos humanos dentro de los límites impuestos por la concepción centrada en el Estado

19 Beitz 2009, pp. 39-40.

20 Precisamente debido a las amplias implicaciones de aceptar obligaciones en materia de derechos humanos, la modificación del Acuerdo sobre los Aspectos de los Derechos de Propiedad Intelectual sobre patentes farmacéuticas emprendida por la OMC, por usar un ejemplo del propio Beitz, evita cuidadosamente el uso del término «derechos humanos» en los documentos oficiales. En lugar de emplear el término «derecho a la salud» se emplean expresiones menos comprometidas, como «preocupación por la salud pública»; en lugar de referirse a las obligaciones de los miembros de la OMC de proteger el derecho humano de los ciudadanos a la salud (y al acceso a medicamentos), se emplean expresiones menos comprometidas como las siguientes: «el Acuerdo puede y debe interpretarse e implementarse de un modo que apoye el derecho de los miembros de la OMC a proteger la salud pública y, en particular, a promover el acceso de todos a los medicamentos» (cursiva mía). Para más información sobre esta reforma en concreto ver http://www.wto.org/english/tratop_e/trips_e/implem_para6_e.htm. En Herstermeyer 2007 puede encontrarse un análisis excelente de las obligaciones de la OMC en materia de derechos humanos en relación con el Acuerdo sobre los Aspectos de los Derechos de Propiedad Intelectual y el derecho a la salud. 
que él defiende. Apelar a la protección de los derechos humanos sólo puede proporcionar una razón válida para reformar regulaciones económicas globales si las instituciones encargadas de «implementar» esa reforma tienen ellas mismas la obligación de proteger los derechos humanos. La plausibilidad normativa de dichas apelaciones habla a favor de abandonar la asignación monista de obligaciones primarias que caracteriza a la concepción centrada en el Estado.

De hecho, algunos de los argumentos del propio Beitz parecen socavar directamente la plausibilidad de la concepción estatista. El objetivo general del libro es ofrecer una interpretación convincente de los derechos humanos como una práctica política y discursiva emergente a nivel global. Beitz insiste en que la concepción práctica de los derechos humanos que él defiende ofrece un modelo normativo, y no meramente descriptivo, de esa práctica emergente ${ }^{21}$. Esto le permite hacer frente a la objeción de que, en la medida en que intenta reconstruir los rasgos de una práctica dada, su enfoque práctico tiene que conferir necesariamente una autoridad excesiva al statu quo. Contra esta objeción Beitz indica que un modelo normativo tiene recursos para criticar la práctica que se propone reconstruir, por ejemplo cuando «las normas de esa práctica son inadecuadas para promover sus objetivos». ${ }^{22}$ Ahora bien, Beitz también reconoce que, a la vista de las estructuras de gobernanza global actualmente existentes, los Estados están condenados a fracasar en la protección de los derechos humanos de sus ciudadanos cuando las violaciones potenciales se deben a regulaciones transnacionales o son perpetradas por actores no estatales. Si tal es el caso, parece que aferrarse a la norma de que sólo los Estados tienen la responsabilidad fundamental de proteger los derechos humanos sólo sirve para exonerar a actores no estatales de toda obligación de proteger los derechos humanos, al tiempo que se reconoce que en ciertos casos dichos actores son los únicos capaces de desempeñar esa función. Me parece que esta situación encaja exactamente en la descripción de Beitz de un caso en que la norma de una práctica es «inadecuada para promover sus propios objetivos». Si es así, la concepción práctica dispone de recursos para adoptar una postura crítica hacia la norma estatista, precisamente en la medida en que esta norma es inadecuada para promover el objetivo fundamental de dicha práctica, a saber, asegurar la protección de los derechos humanos a escala mundial. Vistas así las cosas parece que, en contra de las afir-

21 Dado que el foco de mi análisis aquí es la concepción estatista de las obligaciones de derechos humanos, no voy a abordar aquí la compleja cuestión de si la concepción práctica ofrece una interpretación plausible (o incluso la más plausible) de la naturaleza de los derechos humanos de entre las diferentes interpretaciones contendientes en el debate actual. Para otras versiones dentro de la amplia familia de concepciones políticas de los derechos humanos cf. Rawls 1999, Pogge 2002, Raz 2007. Las alternativas fundamentales a la concepción práctica que Beitz discute en su libro son las que él denomina concepciones naturalistas (cf. Cranston 1973, Griffin 2008) y concepciones basadas en el acuerdo (cf. Taylor 1999, Cohen 2004).

22 Beitz 2009, p. 105. 
maciones de Beitz, la concepción práctica ofrece una justificación fuerte a favor de una norma pluralista, y en contra de la norma exclusivamente estatista, como guía apropiada de la práctica de derechos humanos bajo las condiciones de globalización actuales ${ }^{23}$. El argumento que Beitz aduce en contra de esta alternativa es que el modelo que el propone debe ajustarse descriptivamente a la práctica actual, y por tanto no debe modificarse mientras la práctica misma no cambie. ${ }^{24}$ Sin embargo, esto parece socavar cualquier función de guía de la acción que el modelo pueda tener en relación con la práctica actual. Con ello, la concepción práctica de los derechos humanos se expone a la acusación de conferir «demasiada autoridad al statu quo al tomar como dada una práctica existente» ${ }^{25}$, algo que la argumentación del propio Beitz se propone expresamente refutar.

${ }^{23}$ Como ya indiqué antes, evaluar la plausibilidad de la concepción práctica en tanto que interpretación de la naturaleza de los derechos humanos está más allá del foco de discusión de este artículo. Aunque comparto simpatías con la concepción práctica, la razón fundamental para centrarme en ella aquí, sin embargo, es porque puede parecer la concepción más difícil desde la que cuestionar la norma estatista, dado que esta norma es de hecho predominante en la práctica actual. Ahora bien, como intento mostrar en mi argumentación, esta impresión es errónea, pues la concepción práctica no se guía por los rasgos fácticos de la práctica actual sino por los objetivos normativos subyacentes a la misma. Dado que el objetivo fundamental de esta práctica es garantizar la protección de los derechos humanos a escala mundial y que, en las condiciones actuales, este objetivo se ve seriamente menoscabado a menos que las normas de derechos humanos regulen la conducta de otros actores poderosos y no sólo de los estados una concepción pluralista de las obligaciones de derechos humanos parece perfectamente justificada desde el punto de vista de la concepción práctica. En comparación, otras concepciones de los derechos humanos no plantean un desafío similar a la hora de defender una concepción pluralista de las obligaciones de derechos humanos, dado que la afirmación de que los derechos humanos consisten «en un grupo de normas para regular el comportamiento de los gobiernos» ni es necesaria ni especialmente plausible fuera de los límites inherentes a la concepción práctica. Si se toma en serio lo que la Declaración Universal de los Derechos Humanos indica, parece claro que los derechos humanos son, sobre todo, derechos que todo ser humano posee con independencia de toda demarcación política. Incluso si uno adopta una concepción institucional de los derechos humanos, nada en la Declaración sugiere que los Estados sean las únicas instituciones con obligaciones de proteger los derechos humanos. De hecho, como indica el propio Beitz, el artículo 28 parece directamente refutar el supuesto estatista al establecer una conexión explícita entre los derechos humanos y el orden internacional («toda persona tiene derecho a que se establezca un orden social e internacional en el que los derechos y libertades proclamados en esta Declaración se hagan plenamente efectivos»). Según este artículo, las obligaciones de derechos humanos recaen en todas aquellas instituciones que sean responsables del orden internacional en un momento histórico determinado, tanto si son Estados como si no. Para un ejemplo de una concepción institucional de los derechos humanos que no está centrada en el Estado cf. Pogge 2002, donde los derechos humanos se definen del siguiente modo «un derecho humano a X incluye la exigencia de que, en la medida en que sea razonablemente posible, toda institución social coercitiva sea diseñada de tal modo que todos los seres humanos afectados por ella tengan acceso asegurado a X» (p. 46; cursiva mía).

${ }_{24}$ Para algunas pruebas empíricas en contra de la afirmación de que la práctica actual de los derechos humanos está exclusivamente centrada en el Estado, cf. Clapham 2006 y Reinisch 2005.

25 Beitz 2009, p. 105. 
En mi opinión, hay muy buenas razones para no conferir demasiada autoridad al statu quo al aceptar como dada la norma estatista. Una concepción de los derechos humanos que aspira a dar cuenta de la importancia y el significado de la práctica de los derechos humanos difícilmente puede ser plausible si resulta que, de acuerdo con dicha concepción, el objetivo mismo de esta práctica (a saber, asegurar la protección universal de los derechos humanos) ${ }^{26}$ está a priori condenado al fracaso en circunstancias actuales. Esta conclusión negativa, sin embargo, parece inevitable mientras no se pueda cerrar el hiato de responsabilidad que resulta de la asignación monista de obligaciones de protección de derechos humanos a los Estados. Todos están de acuerdo en que no es posible garantizar la protección de los derechos humanos a escala mundial a menos que las regulaciones económicas globales no imposibiliten de hecho dicha protección. En vista de esta situación, no basta con que los defensores de la concepción estatista indiquen, como hace Beitz, que existen vías legales por las que se podrían modificar regulaciones económicas globales. Lo que ha de mostrarse es que existe alguna vía (legalmente efectiva) de garantizar que dichas regulaciones serán modificadas efectivamente. Esto, a su vez, requiere identificar actores que tienen tanto la obligación como la capacidad legal efectiva de llevar a cabo dicha modificación. Esta tarea, sin embargo, parece insoluble desde los supuestos de la concepción estatista, puesto que los actores que tienen la obligación (los estados particulares) no tienen la capacidad legal de llevar a cabo tal modificación y los actores que tienen la capacidad legal (la OMC, el FMI o el Banco Mundial) no tienen la obligación. Es verdad que, de acuerdo con la concepción estatista, el fracaso de un estado en proteger los derechos humanos puede proporcionar a agentes externos capaces y apropiadamente situados (como actores no estatales) razones pro tanto para actuar. Sin embargo, como Beitz reconoce abiertamente, «esto significa que, en general, el fracaso en proteger los derechos humanos en una sociedad no requerirá acción por parte de agentes externos» (p. 117; subrayado mío). Esta es la dificultad que, en mi opinión, la concepción estatista no puede superar ni en su interpretación más favorable o caritativa. ${ }^{27}$

Ahora bien, la cuestión que importa aquí, por supuesto, es si existe una alternativa plausible al statu quo. ¿Es plausible afirmar que actores no estatales, como la OMC, tienen la obligación de proteger los derechos huma-

26 Este objetivo está identificado explícitamente en los documentos principales sobre derechos humanos. El artículo I de la Carta de de las Naciones Unidas identifica «promover y fomentar el respeto a los derechos humanos y a las libertades fundamentales para todos» como uno de sus objetivos principales. En el preámbulo de la Declaración Universal de los Derechos Humanos se indica que «La Asamblea General proclama la presente DECLARACIÓN UNIVERSAL DE DERECHOS HUMANOS... a fin de que tanto los individuos como las instituciones... promuevan ... el respeto a estos derechos y libertades, y aseguren, por medidas progresivas de carácter nacional e internacional, su reconocimiento y aplicación universales y efectivos» (cursiva mía).

27 Agradezco a Charles Beitz por hacerme ver la necesidad de clarificar este punto. 
nos? ¿No requeriría esto que la OMC dejara de ser una asociación voluntaria diseñada para facilitar el comercio entre sus miembros, y que se convirtiese en una organización de derechos humanos? A fin de mostrar que una alternativa a la adscripción monista de obligaciones, típica de la concepción centrada en el Estado, no necesita conducir a consecuencias tan poco plausibles, es importante prestar atención al ambiguo significado de la noción de «protección» de los derechos humanos que hemos utilizado hasta el momento. Si, adoptando la terminología estándar, distinguimos entre el deber de respetar, proteger y realizar los derechos humanos, ${ }^{28}$ está claro que hablar de la obligación de proteger los derechos humanos puede tener diferentes significados, dependiendo de si esta expresión se interpreta en el sentido restringido de (meramente) respetar los derechos humanos, o bien en el sentido, más ambicioso, de realizar (positivamente) los derechos humanos. Mientras en el segundo y más amplio sentido es ciertamente muy plausible afirmar que los Estados tienen la responsabilidad de proporcionar las garantías, títulos y servicios necesarios para realizar (es decir, promover y hacer cumplir) los derechos humanos de sus ciudadanos, no parece plausible en absoluto afirmar que los Estados son los únicos actores que tienen la responsabilidad de respetar los derechos humanos de sus ciudadanos. La obligación de respetar los derechos humanos, en el sentido de no contribuir a su violación, parece ser una obligación universal, que vincula tanto a los Estados como a actores no estatales.

En este contexto, es importante no asimilar la distinción entre estos dos sentidos de «proteger» los derechos humanos a la distinción entre acción y omisión, según la cual la «realización» de los derechos humanos requiere acción positiva, mientras que el «respeto» sólo requiere auto-limitación. Puede haber contextos en los que esta distinción sea útil, pero el contexto presente no es uno de ellos. La inacción puede ser una forma apropiada de cumplir con la obligación de respetar los derechos humanos por parte de algunos actores no estatales en algunos contextos, pero ciertamente no en todos. Una corporación multinacional puede decidir suspender su implicación en un país con un alto récord de violaciones de los derechos humanos a fin de cumplir con su obligación de respetar los derechos humanos. Sin embargo, esta opción no la tienen las instituciones financieras internacionales encargadas de regular diferentes sectores del orden económico global (tales como la OMC, el FMI o el Banco Mundial). Mientras su misión sea implementar regulaciones y políticas económicas globales, no tienen otra opción que escoger activamente entre alternativas, e implementar una regulación u otra. En relación con estas instituciones, la diferencia relevante entre «respetar» y «promover» los dere-

28 Esta terminología fue introducida por Eide 1987. La concepción de la estructura de múltiples obligaciones aplicable a todos los derechos humanos, expresada en esta división tripartita, fue propuesta originalmente por Shue 1980, si bien con una terminología diferente. 
chos humanos no es la diferencia entre acción y omisión. Es la diferencia entre adoptar como objetivo propio el cumplimiento de los derechos humanos a escala global (es decir, convertirse en organizaciones de derechos humanos) y aceptar la obligación de asegurar que las regulaciones y medidas que implementan para alcanzar sus propios objetivos (la liberalización del comercio, la estabilidad financiera, el crecimiento económico, etc.) no impiden la protección de los derechos humanos (es decir, no impiden a ninguno de sus miembros cumplir sus obligaciones en materia de derechos humanos). ${ }^{29}$ A la luz de esta distinción, parece claro que la cuestión de si estas instituciones deberían o no incluir entre sus estatutos legales el objetivo de promover y realizar activamente los derechos humanos, o si esta función debería ser relegada a los Estados y a las instituciones de derechos humanos, no tiene nada que ver con la cuestión, completamente diferente, de si estas instituciones están sujetas a las leyes internacionales que obligan a respetar los derechos humanos $\mathrm{y}$, por tanto, han de asegurar que las regulaciones que implementan (con el fin de alcanzar sus objetivos específicos) no tienen un impacto negativo en el disfrute de los derechos humanos a escala mundial. Mientras que la primera cuestión es compleja, y por tanto una respuesta afirmativa puede ser controvertida, la respuesta positiva a la segunda cuestión parece difícilmente cuestionable desde un punto de vista normativo. ${ }^{30}$ Una vez establecida la distinción, es difícil imaginar que estas instituciones pudieran defender abiertamente una interpretación de sus obligaciones legales según la cual éstas consisten en perseguir obstinadamente sus objetivos económicos específicos desentendiéndose totalmente del impacto que puedan tener en los derechos humanos más básicos de la población mundial.

De hecho, si se examinan las declaraciones oficiales de estas instituciones en relación con la cuestión de sus obligaciones en materia de derechos humanos, casi invariablemente se corrobora la combinación de afirmaciones que hemos mencionado, a saber, el rechazo de la obligación de promover o hacer cumplir directamente los derechos humanos como parte de su mandato legal (lo que las convertiría en instituciones de derechos humanos), y el reconocimiento de la obligación de asegurar que las medidas y regulaciones que estas instituciones aplican no impiden el disfrute de los derechos humanos a escala mundial. Un ejemplo de esta posición puede encontrarse en una carta firmada por Sergio Pereira Leite, Director Adjunto de la oficina europea del FMI, titulada «El Fondo Monetario Internacional y los Derechos Humanos» y publicada en Le Monde en septiembre de 2001. Esta carta está disponible en la web

29 Algunos autores llaman a esta obligación el «deber de vigilancia», es decir, el deber de asegurar en la media de lo posible que las acciones de la institución no tienen un impacto negativo en la capacidad de sus miembros de cumplir sus obligaciones internacionales en materia de derechos humanos. Cf. Darrow 2003, pp. 132, 137.

30 Una panorámica de la vasta bibliografía jurídica sobre este asunto puede encontrarse en Skogly 2001. 
oficial del FMI. ${ }^{31}$ Refiriéndose al rechazo a incluir la implementación de los derechos humanos como parte del mandato legal del FMI, el autor afirma lo siguiente:

Desde 1999 el FMI ha subrayado el papel central de la reducción de la pobreza en la estrategia del Fondo para los países con bajos ingresos (...). Es importante recordar, sin embargo, que la estrategia de reducción de la pobreza ha de permanecer en las manos del propio país. Si bien hay que dar a los defensores de los derechos humanos todas las oportunidades para participar en los documentos estratégicos de lucha contra la pobreza, éstos no deben esperar que el FMI imponga condiciones de derechos humanos en su asistencia a los países miembros. El FMI simplemente no tiene la competencia requerida para hacer juicios en este terreno (Cursiva mía).

Pero tras afirmar la ausencia de obligación legal y la falta de competencia en el terreno de la promoción y el cumplimiento de los derechos humanos, encontramos también el reconocimiento de la obligación de asegurar que las medidas del FMI no tienen un impacto negativo en el disfrute de los derechos humanos:

El Fondo Monetario Internacional reconoce que debería estar atento a cualquier efecto colateral negativo de las medidas que propone. En tales casos, a menudo es necesario introducir redes de seguridad adecuadas para ayudar a aliviar las consecuencias sociales adversas. Esto es algo que el FMI acepta plenamente (...) El FMI debe esforzarse en estar abierto a la crítica y a las iniciativas de cambiar sus medidas cuando los resultados sean decepcionantes. Pero debe reconocerse que el FMI se creó para promover la cooperación monetaria internacional y el ajuste ordenado de la balanza de pagos (Cursiva mía).

De manera similar, en la vasta y compleja bibliografía jurídica actual sobre el comercio y los derechos humanos, los especialistas disienten sobre si la OMC tiene la obligación de proteger los derechos humanos. Sin embargo, si se presta atención a la diferencia entre los dos sentidos, completamente diferentes, de la «protección» de los derechos humanos a que nos hemos referido antes, el espacio para la controversia se reduce bastante deprisa. Interpretando dicha protección en sentido amplio, hay desacuerdo sobre si la protección de los derechos humanos es parte del mandato legal de la OMC. Por un lado, muchos juristas responden negativamente a esa cuestión. En la mayor parte

31 La carta puede encontrarse en la siguiente página web del FMI: http://www.imf.org/external/np/vc/2001/090401.htm. Posteriormente se publicó una versión más larga de la carta en la revista del FMI Finance \& Development. Esta versión más larga también está disponible en la web del FMI: http://209.133.61.129/external/pubs/ft/fandd/2001/12/leite.htm. En la versión más larga son reveladores los títulos de las secciones en las que se encuentra cada uno de los pasajes citados. Son, respectivamente, los siguientes: «¿Cuál es la contribución del FMI a los derechos humanos?», y «Los programas sostenidos por el FMI, ¿dañan los derechos económicos, sociales y culturales?» 
de los casos justifican esta posición señalando que el objetivo de proteger los derechos humanos no se menciona en ninguno de los documentos fundacionales de la OMC como parte de su mandato. Por otro lado, sin embargo, algunos juristas argumentan que el objetivo de proteger los derechos humanos puede derivarse de algunos de los objetivos específicos establecidos en el Preámbulo de la OMC, por ejemplo el objetivo de aumentar el nivel de vida y del desarrollo sostenible. ${ }^{32}$ Sea como fuere, parece claro que este interesante debate no está directamente relacionado con la cuestión, completamente distinta, de si la OMC está sujeta a la obligación de proteger los derechos humanos en el sentido restringido de estar obligada a respetar las leyes internacionales de derechos humanos. ${ }^{33}$ Todos los especialistas responden afirmativamente a esta cuestión, ${ }^{34}$ aunque hay ciertamente bastante desacuerdo acerca del alcance y las implicaciones precisas de esta obligación, así como acerca de la variedad de medios legales y técnicos para su implementación. Las propuestas menos ambiciosas atribuyen las principales obligaciones a las instituciones de resolución de disputas, y analizan los diferentes instrumentos legales de que disponen estas instituciones cuando juzgan casos presentados por Estados miembros (tales casos pueden abarcar desde la concesión de excepciones a países concretos hasta la exigencia, de mayores consecuencias, de que la regulación en cuestión sea revisada por los expertos, a fin de evitar cualquier conflicto con la legislación internacional relevante en materia de derechos humanos). ${ }^{35}$ Las propuestas más ambiciosas incluyen además la obligación de evaluar el impacto que tendrían determinadas medidas comerciales en la capacidad de proteger los derechos humanos durante las primeras fases de negociación y elaboración, y no sólo en la fase posterior de imple-

32 Cf. Zagel 2005. Incluso los juristas que intentan derivar de alguno de los objetivos específicos de la OMC la obligación de proteger los derechos humanos coinciden en que esta institución no tiene el mandato de hacer cumplir los derechos humanos, sino sólo los estatutos de la OMC. Estos autores afirman más bien que la legislación de la OMC debe interpretarse e implementarse de modo consistente con cualquier legislación relevante en materia de derechos humanos. Sobre la importancia de esta distinción cf. Clapham 2006, pp. 164 y sigs.

33 De hecho, en 2001 el Secretariado de la OMC reconoció que la OMC está sujeta a la legislación internacional normal en materia de derechos humanos. Cf. UN Doc. E/CN.4/Sub.2/ 2001/SR.12, para. 24, protocolo del 12. ${ }^{\circ}$ encuentro, del 8 de agosto de 2001.

34 No es sorprendente que los juristas coincidan en que la legislación de la OMC debe interpretarse de un modo consistente con la legislación internacional sobre derechos humanos (esta opinión es compartida por algunos miembros de la División de Asuntos Legales de la OMC. Un ejemplo puede encontrarse en Marceau 2002, p. 755.) Sin embargo, los expertos siguen diferentes vías para derivar las obligaciones de respetar los derechos humanos a partir de los rasgos específicos de la OMC. Una de ellas consiste en señalar que el Artículo XXI (c) del GATT permite desviarse de las obligaciones del GATT si se hace en cumplimiento de las obligaciones que el Estado miembro contrae en virtud de la Carta de la ONU, y una de las principales obligaciones de todos los miembros de la ONU es proteger los derechos humanos. Un ejemplo puede leerse en Zagel 2005.

35 Para una buena panorámica de las principales propuestas actualmente en discusión entre los especialistas, cf. Herstermeyer 2007, pp. 209-229. 
mentación. ${ }^{36}$ Esta obligación podría anclarse institucionalmente mediante el establecimiento de una «División de Comercio y Derechos Humanos» en la secretaría de la OMC que proporcionara asistencia técnica en la elaboración de dichos análisis de impacto en materia de protección de derechos humanos. ${ }^{37}$

La situación es similar en el caso del Banco Mundial. Aunque la interpretación oficial del mandato legal del Banco no incluye el promover o implementar los derechos humanos, el Banco reconoce su obligación de respetar los derechos humanos. ${ }^{38}$ Sin embargo, más allá de este reconocimiento abstracto hay al menos dos rasgos de la estructura y las prácticas actuales del Banco que ofrecen una base institucional que permitiría anclar la obligación de respetar los derechos humanos en las actividades de dicha institución. En contraste con la OMC, ya es parte de la práctica actual del Banco la realización de «análisis de impacto social» diseñados para calibrar el impacto social de sus propias medidas y programas en los países de referencia, en relación con el objetivo de promover el «bienestar o la prosperidad de los diferentes grupos afectados, con especial atención hacia los más pobres y vulnerables». ${ }^{39}$ Aunque el historial de implementación de este tipo de análisis respecto a la mayor parte de los programas apoyados por el Banco es bastante pobre, su existencia indica que es perfectamente viable incorporar a las medidas operativas del Banco evaluaciones de impacto sobre los derechos humanos que sean sensibles al amplio espectro de factores relevantes para la protección de los derechos humanos en el contexto y las circunstancias específicas de los diferentes países, y que por consiguiente sirvan de guía para decidir si y cómo debe llevarse a cabo una operación o un programa concreto. Esta práctica también está presente en el FMI, aunque en menor medida. Otra institución perteneciente al Banco que promete un anclaje institucional más fuerte de las obligaciones vinculadas a los derechos humanos en las operaciones de esta institución es el Panel de Inspección creado en 1993. Su mandato consiste en revisar las quejas de cualquier grupo de particulares que teman sufrir o aleguen estar sufriendo los efectos materiales adversos de los fallos del Banco en el seguimiento de sus medidas y procedimientos operativos. Obviamente, cuanto más arraigada se encuentre la obligación de respetar los derechos humanos en las operaciones del Banco, tanto mayor será la capacidad de esta institución para exigir que el Banco rinda cuentas de su impacto sobre los derechos humanos. Desde un punto de vista normativo, la creación de este Panel tiene además la importancia de constituir el primer reconocimiento formal de que las organizaciones internacionales no sólo son respon-

36 Cf. Zagel 2005, pp. 30-31. Una propuesta similar, aunque sin referencias específicas a los derechos humanos, se encuentra en Stiglitz y Charlton 2005, p. 7.

37 Cf. Zagel 2007, p. 367.

38 Cf. Banco Mundial 2008.

39 Banco Mundial,2002, 2. 
sables ante los Estados, sino ante individuos o colectivos particulares afectados por sus operaciones, independientemente de la relación que tengan las organizaciones o los actores particulares con los Estados que forman parte de esas organizaciones. ${ }^{40}$

Esto nos retrotrae a la cuestión que planteé al principio de si es conceptualmente plausible esperar que los miembros de instituciones globales que representan a Estados sean responsables ante todos los que tienen que acatar sus decisiones, al tiempo que siguen siendo responsables ante los ciudadanos de sus propios países por las obligaciones especiales que tienen con ellos. Me parece que si la cuestión se plantea en términos de las obligaciones de instituciones globales en materia de protección de los derechos humanos, el dilema conceptual pierde buena parte de su plausibilidad. Parece perfectamente coherente afirmar que los miembros de las instituciones globales tienen, como representantes de sus Estados, la responsabilidad especial de promover los intereses y derechos de sus propios ciudadanos tan intensamente como puedan, mientras respeten los límites impuestos por la obligación general, que tienen como agentes de instituciones globales, de asegurar que sus decisiones colectivas no influyen negativamente en la posibilidad de proteger los derechos humanos a escala mundial. La analogía con el nivel nacional parece suficiente para mostrar la plausibilidad normativa de esta concepción de obligaciones plurales. Los representantes de las diferentes regiones de un país dotado de una estructura política federal pueden tener la responsabilidad especial de promover tan intensamente como puedan los intereses y derechos de los ciudadanos de las regiones que representan, siempre que respeten los límites impuestos por la obligación, que les corresponde como miembros de una institución nacional, de asegurar que sus decisiones colectivas no influyen negativamente en la posibilidad de proteger los derechos constitucionales de todos los ciudadanos.

Con esto no quiero sugerir que la analogía entre el nivel nacional y el nivel global sea perfecta, ni que las soluciones institucionales establecidas a nivel nacional (tales como un Tribunal Constitucional con autoridad para interpretar la Constitución) serían adecuadas o deseables a nivel global. Una diferencia importante entre estos dos casos estriba en que a nivel nacional todos los ciudadanos tienen los mismos derechos constitucionales, mientras que a nivel internacional los derechos constitucionales de los ciudadanos pueden ser mucho más extensos y exigentes que los derechos humanos que se reconocen a todos los ciudadanos del mundo. Por esta razón, la propuesta que defiendo es compatible con la afirmación de Nagel de que las obligaciones de justicia social entre los ciudadanos de un Estado nacional particular son ma-

40 Cf. Bradlow 1994, p. 554. Para ver otros ejemplos de mecanismos de rendición de cuentas adoptados por otras instituciones internacionales en respuesta a las crecientes demandas de «buena gobernanza», cf. Reinisch 2005, pp. 50 y sigs. 
yores y cualitativamente diferentes de las obligaciones que tienen estos compatriotas hacia los ciudadanos de otros países ${ }^{41}$. Sin embargo, al atribuir obligaciones en materia de derechos humanos a las instituciones globales, mi propuesta es incompatible con la afirmación de Nagel según la cual las acciones y decisiones de las instituciones globales no alcanzan «el nivel de acción colectiva necesario para dar lugar a demandas de justicia, incluso en una forma diluida (...). La relación sigue siendo esencialmente de negociación, mientras no se dé el salto de crear una autoridad soberana colectivamente autorizada. Según la concepción política "discontinua" que yo defiendo, los tratados o acuerdos internacionales, como por ejemplo los que establecen las reglas del comercio (...), son contratos "puros", y nada garantiza la justicia de sus resultados.» ${ }^{42}$

La interpretación de Nagel de las regulaciones de instituciones internacionales como la OMC como «contratos puros» (y, por tanto, como exentos de toda obligación de justicia, por mínima que sea) parece motivada por un falso dilema. Como vimos al principio, la argumentación de Nagel parece asumir que sólo tenemos dos opciones conceptuales: o bien los representantes de los Estados tienen la responsabilidad de promover los intereses y derechos de sus propios ciudadanos o bien tienen la responsabilidad colectiva de promover por igual los intereses y derechos de la ciudadanía combinada de todos los Estados implicados ${ }^{43}$. Si esas fueran las únicas opciones, la responsabilidad inclusiva parecería efectivamente incompatible con la responsabilidad

41 Al indicar la compatibilidad de mi propuesta con la concepción estatista de la justicia social de Nagel no pretendo afirmar la validez de dicha concepción sino sólo mostrar que, incluso aunque uno la acepte como valida, no se puede extraer de ella razones convincentes para rechazar la asignación de obligaciones en materia de derechos humanos a instituciones globales.

42 Nagel 2005, p. 141. Para una convincente crítica de esta afirmación cf. Cohen y Sabel 2006, p. 171.

${ }_{43}$ Este supuesto está muy extendido, no sólo entre críticos como Nagel, sino incluso entre aquéllos que defienden que los miembros de instituciones globales y redes regionales deberían estar sujetos a responsabilidades tanto domésticas como globales. Slaughter 2005 ofrece un claro ejemplo. Por un lado afirma, de modo muy plausible en mi opinión, que los miembros de redes gubernamentales «primero han de ser responsables ante aquellos que representan a nivel doméstico por sus actividades transgubernamentales del mismo modo que lo son por sus actividades domésticas. Segundo, en tanto que participantes en estructuras de gobernanza global deben tener un código operativo básico que tenga en cuenta los intereses y derechos de todo el mundo» (p. 39; cursiva mía). Sin embargo, su interpretación de esta segunda responsabilidad parece demasiado fuerte como para evitar la objeción de que no deja espacio para el ejercicio de la primera responsabilidad. Slaughter explica: «incluso si los participantes en redes gubernamentales fueran adecuadamente responsables ante sus representados domésticos, qué deber tienen para con otras naciones? Puede parecer una pregunta extraña, pero si esas redes constituyen realmente estructuras primarias de gobernanza global ... tendrían que estar sujetas a normas tanto globales como nacionales. Serían responsables de formular e implementar colectivamente políticas en el interés público global» (p. 51; cursiva mía). Desgraciadamente, Slaughter no explica cómo ambas responsabilidades pueden ejercitarse simultáneamente en la ausencia de un Estado mundial. 
doméstica, pues ejercer la responsabilidad de promover los intereses de todos los ciudadanos del mundo por igual no dejaría espacio para ejercitar la responsabilidad de promover específicamente los intereses particulares de los conciudadanos. En la ausencia de un Estado mundial, los representantes que intentaran cumplir las exigencias de una responsabilidad inclusiva estarían sujetos al reproche constante de desatender las expectativas legítimas de los propios representados.

Ahora bien, una vez que la cuestión de la adecuada responsabilidad de las instituciones globales se interpreta en términos de la obligación de respetar los derechos humanos, parece abrirse una vía por la que escapar al dilema de Nagel, pues podemos ver cómo las responsabilidades globales y domésticas de los representantes de los Estados miembros son significativamente diferentes y, por tanto, pueden ejercitarse simultáneamente. En la medida en que esto es así es difícil ver cómo los ciudadanos de cualquier país podrían esperar o exigir legítimamente cualquier otra cosa de sus propios representantes. Tomemos como ejemplo la OMC, y aceptemos, por mor del argumento, la opinión, muy extendida, de que esta institución está diseñada simplemente para facilitar las negociaciones entre partes interesadas que buscan su propio provecho. ${ }^{44}$ Incluso en ese escenario estratégico, una cosa es esperar que los

44 Pese al compromiso oficial de la OMC con el objetivo de aumentar el nivel de vida y de desarrollo sostenible, muchos críticos consideran que el diseño de la OMC como una asociación voluntaria para facilitar el comercio entre sus miembros la convierte simplemente en un mercado para la negociación, en el que sus miembros no intentan acordar colectivamente las mejores medidas comerciales para todos, sino que intentan negociar el mejor acuerdo para sí mismos. En su libro The Bottom Billion, Collier ofrece una expresiva caracterización de la $\mathrm{OMC}$ en esa línea: «[La OMC] no es una institución que persigue unos objetivos, sino más bien un mercado. El Secretariado de la OMC simplemente está ahí para levantar el puesto cada mañana, barrer el suelo cada tarde y regular el horario de apertura. Lo que sucede allí está determinado por las negociaciones (...). La ronda de negociaciones comerciales fue calificada de «ronda de desarrollo», pero tales etiquetas no tienen realmente ningún contenido en una organización diseñada para el regateo. Del mismo modo podría llamarse una «ronda de desarrollo» al comercio de mañana en eBay. Las negociaciones comerciales están ahí para conseguir el mejor trato al país propio, definido en términos de un mínimo de apertura del mercado doméstico por un máximo de apertura del de los otros» (pp. 170-171). La evolución legal de la OMC y de sus instituciones internas sugiere que probablemente esta estrecha valoración de su funcionamiento será cada vez menos acertada, pero incluso si se acepta como una descripción acertada de cómo entienden el papel de esta institución tanto sus miembros como los ciudadanos a los que representan (como hago yo en este artículo por mor del argumento), sigue pareciendo enteramente injustificado afirmar que esta institución no tiene la obligación de respetar los derechos humanos. Debe notarse que, pese a su cínica valoración del diseño actual de la OMC, Collier no ve en principio ningún impedimento para su ambiciosa propuesta de reforma de esta institución, que incluye «añadir una función de transferencia a su función de negociación», con el propósito concreto de ayudar a los países más pobres a costa de los más poderosos intereses económicos de los países ricos. Como explica Collier, «con "transferencia" me refiero a una reducción no recíproca de las barreras comerciales hacia los mil millones más pobres: un regalo, no un trato (...). El Secretariado de la OMC debería encargarse de negociar ese regalo en la primera fase de cada ronda» (p. 171). Como antiguo director del Banco Mundial, 
representantes promuevan tan intensamente como puedan los intereses y derechos de sus representados, y otra cosa muy distinta es esperar que promuevan esos intereses y derechos tan intensamente como puedan, incluso si eso implica violaciones evidentes (y previsibles) de los derechos humanos de otros ${ }^{45}$. Dado que para evitar esto último no es necesario tratar los intereses y derechos de todos los ciudadanos del mundo por igual más allá del umbral relevante, la obligación de respetar los derechos humanos compartida por todos los miembros de una institución global parece perfectamente compatible con la persecución del objetivo estratégico de promover los intereses y derechos de los propios representados tan intensamente como sea posible, dentro de los límites establecidos por la obligación prioritaria anterior.

Obvia decir que las dificultades prácticas a la hora de implementar mecanismos que anclen la obligación de proteger los derechos humanos en instituciones globales son inmensas. Más allá del temor habitual de que tales mecanismos puedan ser manipulados por los poderosos tanto como lo son los mecanismos actuales, hay que añadir el problema de que actualmente no disponemos de un conjunto coherente de criterios para evaluar el impacto concreto de las regulaciones económicas globales sobre la protección de los derechos humanos. Obviamente, tampoco es de esperar que esté disponible en el futuro mientras no haya un acuerdo acerca de su necesidad entre los miembros de la comunidad internacional. En cualquier caso, el desarrollo de tal conjunto de criterios concretos sería crucial para coordinar el trabajo de las diferentes instituciones financieras internacionales, y por tanto para alcanzar una mayor coherencia en las políticas económicas globales. Ciertamente, lograr un acuerdo en torno a criterios concretos de protección de los derechos humanos básicos por parte de la comunidad internacional puede ser muy difícil así como controvertido, en la medida en que pueda percibirse como politizado o sesgado ideológicamente. Pero por imperfectos, controvertidos o revisables que sean tales acuerdos, su implementación supondría sin duda una ventaja frente a la alternativa de desconsiderar por completo el impacto de las regulaciones económicas globales sobre los derechos humanos en los procesos de decisión de las instituciones globales. Establecer mecanismos internos

Collier toma la evolución del Banco como modelo para la OMC: «El Banco evolucionó al añadir una función de transferencia orientada hacia los países con bajos ingresos a lo que originalmente era una función de asistencia mutua de los países ricos. Esto es lo que debería suceder con la $\mathrm{OMC} \gg($ ibid.).

${ }^{45} \mathrm{La}$ reciente disculpa pública del presidente Clinton por apoyar políticas comerciales que destruyeron la producción de arroz en Haití es una clara ilustración de la plausibilidad de la concepción de responsabilidad inclusiva defendida aquí. El 10 de marzo de este año, hablando ante el comité para relaciones extranjeras del Senado estadounidense sobre su apoyo a cortes drásticos en los aranceles para la importación de arroz estadounidense en Haití, Clinton declaró: «Puede que fuera bueno para algunos de mis granjeros en Arkansas, pero no ha funcionado. Tengo que vivir cada día con las consecuencias de la perdida de capacidad de Haiti de producir una cosecha de arroz para alimentar a su población por culpa de lo que yo hice.» 
de responsabilidad en las instituciones globales a fin de garantizar el cumplimiento de la obligación de respetar los derechos humanos puede que sólo permitiera prevenir los casos más evidentes de graves violaciones de los derechos humanos, si los criterios acordados son mínimos o se han formulado de un modo excesivamente estrecho. Pero a falta de cualquier mecanismo de este tipo, no hay razón alguna para esperar que ni las violaciones más crasas y obvias se prevengan en absoluto. Incluso esa modesta aspiración parece inalcanzable mientras no exista un acuerdo firme acerca de la necesidad y la corrección normativa de anclar legalmente la obligación de respetar los derechos humanos en las instituciones globales.

\section{BIBLIOGRAFÍA}

Alston, P. (ed.) (2005): Non-State Actors and Human Rights, Oxford U.P.

BeITZ, C. (2009): The Idea of Human Rights, Oxford, Oxford U.P.

Bohman, J. (2007): Democracy across Borders, Cambridge, MA: MIT Press.

BRADLOW, D. (1994): «International Organizations and Private Complaints: The Case of the World Bank Inspection Panel», Virginia Journal of International Law, 34/3, 553-613.

Clapham, A. (2006): Human Rights Obligations of Non-State Actors, Oxford, Oxford U.P.

CoHen, J. (2004): «Minimalism about Human Rights», Journal of Political Philosophy, 12, 190-213.

CohEn, J. y SABeL, C. (2005): «Global Democracy?», NYU Journal of International Lawand Politics, 37, 763-797.

— (2006): «Extra Rempublicam Nulla Justitia?», Philosophy \& Public Affairs, 34/2, $147-75$

Collier, P. (2007): The Bottom Billion, Oxford U.P.

CotTier, T.; PAuwelyn, J. y BÜRgi, E. (eds.) (2005): Human Rights and International Trade, Oxford: Oxford U.P.

Cranston, M. (1973): What Are Human Rights?, Londres: Bodley Head.

DAHL, R. (1999): «Can International Organizations Be Democratic? A Skeptic's View», en I. ShaPiro y C. HACKer-Cordón (eds.), Democracy's Edges, Cambridge: Cambridge U.P., 19-36.

DARrow, M. (2003): Between Light and Shadow: The World Bank, the International Moneraty Fund and International Human Rights Law, Oxford: Hart Publishing.

DryzeK, J. (2006): Deliberative Global Politics. Cambridge: Polity Press.

EIDE, A. (1987): The New International Economic Order and the Promotion of Human Rights. Report on the Right to Adequate Food as a Human Right, UN DocE/CN.4/Sub.2/1987/23.

Goodin, R. (2003): «Globalizing Justice», en D. HeLD (ed.), Taming Globalization, Oxford: Polity Press, 68-92.

Griffin, J. (2008): On Human Rights. Oxford: Oxford U.P.

HABERMAS, J. (2008): «A Political Constitution for the Pluralist World Society?», en Between Naturalism and Religion, Cambridge, MA: MIT Press, 312-352. 
Held, D. (2004): Global Covenant. The Social Democratic Alternative to the Washington Consensus, Cambridge: Polity Press.

- (2005): «Democratic Accountability and Political Effectiveness from a Cosmopolitan Perspective», en D. Held y M. Koenig-ArChIBUGi (eds.), Global Governance and Public Accountability, Oxford: Blackwell, 240-267.

Held, D. y Koenig-Archibugi, M. (eds.) (2005): Global Governance and Public Accountability, Oxford: Blackwell.

Herstermeyer, H. (2007): Human Rights and the WTO. The Case of Patents and Access to Medicines, Oxford: Oxford U.P.

KaHLER, M. (2004): «Defining Accountability Up: The Global Economic Multilaterals», en D. Held y M. KoENIG-ARChiBugi (eds.), Global Governance and Public Accountability, Oxford: Blackwell, 8-34.

Keohane, R. (2003): «Global Governance and Democratic Accountability», en D. Held (ed.), Taming Globalization, Oxford: Polity Press, 130-159.

Keohane, R. y NyE, J. (2003): «Redefining Accountability for Global Governance», en M. KAHLER y D. LAKE (ed.) (2003): Governance in a global economy: political authority intransition, Princeton, NJ: Princeton U.P, 2003, 386-411.

LAFONT, C. (2008): «Alternative Visions of a New Global Order: What should Cosmopolitanshope for?», en Ethics \& Global Politics, 1/1-2, 1-20.

Marceau, G. (2002): «WTO Dispute Settlement and Human Rights, European Journal of International Law, 13/4, 753-814.

Nagel, T. (2005): «The Problem of Global Justice», Philosophy \& Public Affairs, $33 / 2,113-47$.

Pauwelyn, J. (2005): «Human Rights in WTO Dispute Settlement», en CotTIER, T., Pauwelyn, J. y E. Bürgi (eds.), Human Rights and International Trade, Oxford: Oxford U.P., 205-231.

PEREIRA, S. (2001): The International Monetary Fund and Human Rights, in http://www.imf.org/external/np/vc/2001/090401.htm. Una versión más extensa en http://209.133.61.129/external/pubs/ft/fandd/2001/12/leite.htm.

Pogge, T. (2002): World Poverty and Human Rights, Cambridge: Polity Press.

Rawls, J. (1999): The Law of Peoples. Cambridge, MA: Harvard U.P.

RAZ, J. (2007): «Human Rights Without Foundations», Oxford Legal Studies Research Paper No. 14, 1-21.

ReINISCH, A. (2005): "The Changing International Legal Framework for Dealing with Non-State Actors», en Alston (ed.), Non-State Actors and Human Rights, Oxford U.P., 37-89.

Schmalz-BRuns, R. (2007): «An den Grenzen der Entstaatlichung. Bemerkungen zu Jürgen Habermas' Modell einer "Weltinnenpolitik ohne Weltregierung"», en P. NIESEN y B. HERBORTH (eds), Anarchie der kommunikativen Freiheit, Frankfurt: Suhrkamp, 369-393.

Shue, H. (1980): Basic Rights. Subsistence, Affluence and U.S. Foreign Policy, Princeton: Princeton U.P.

Skogly, S. (2001): The Human Rights Obligations of the World Bank and the International Monetary Fund, Londres: Cavendish Press.

Slaughter, A.-M. (2005): «Disaggregated Sovereignty: Towards the Public Accountability of Global Government Networks», en D. Held y M. KoeniG- 
Archibugi (eds.), Global Governance and Public Accountability, Oxford: Blackwell, 35-66.

Stiglitz, J. y Charlton, A. (2005): Fair Trade for All. How Trade can PromoteDevelopment, Oxford: Oxford U.P.

WoOdS, N. y NARLIKAR, A. (2001): «Global Governance and the Limits of Accountability: The WTO, the IMF, and the World Bank», International Science Journal 53/170, 569-583.

World BANK (1998): Development and Human Rights: the Role of the World Bank, Washington DC: World Bank.

- (2002): A User's Guide to Poverty and Social Impact Analysis (draftprepared by the Poverty Reduction Group and Social Development Department, 19 April 2002).

Zagel, G. (2005): «WTO and Human Rights: Examining Linkages and Suggesting Convergence», Voices of Development Jurist Paper Series 2/2, 1-37.

- (2007): «Human Rights Accountability of the WTO», Human Rights \& International Legal Discourse 1/2, 335-379. 